\title{
The self-sabotage of conservation: a reply to Manfredo et al.
}

\author{
Christopher D. Ives ${ }^{1}$ and Joern Fischer ${ }^{2}$
}

${ }^{1}$ School of Geography, University of Nottingham, University Park, Nottingham, NG7 2RD, U.K., email chris.ives@ nottingham.ac.uk

${ }^{2}$ Faculty of Sustainability, Leuphana University Lueneburg, Scharnhorststrasse 1, 21335 Lueneburg, Germany

Manfredo et al. (2017) argue for a social-ecological systems approach to understanding value change in conservation. They conclude that conservation scientists ought to work within people's value systems, rather than attempt to change values, because values are deeply embedded within societies' cultures, traditions, and institutions. We strongly agree with using holistic approaches to understand human-environment relationships, including human values. We applaud the authors for exploring directly how value shift occurs and whether it can be influenced intentionally. We also agree that values cannot be changed easily or separated from their sociocultural context.

However, we do not believe Manfredo et al.'s conclusion, namely that one should not attempt to change values, strictly follows from their analyses. Our response should be considered in a spirit of constructive critique. After all, we agree with the focus by Manfredo et al. to a very large extent. Yet, we explain below how, in our view, systems thinking favors the opposite conclusion: that changes in human values, social order, and culture, although difficult, are necessary if the current extinction event is to be halted. Some conservation gains can indeed be made within existing public value orientations; yet working only within existing values and cultural contexts amounts to self-sabotaging conservation. Rather than curbing efforts to shift values, we advocate for more targeted and sophisticated enquiry into how values and associated patterns of culture can be adjusted for the sake of conservation. But before this, it 
is necessary to consider briefly the ways in which value is conceptualized so as to ensure a common understanding in this dialogue.

Scholars from different fields have strict definitions of value, and the term has been applied in different ways in different contexts ( Ives \& Kendal 2014). Manfredo et al. explicitly adopt a social-psychological approach to conceptualizing value (p. 2). Yet, to move the dialogue forward constructively, we think it is important to approach the topic more broadly. Certain values (e.g. capitalism, consumerism) dominate contemporary western society, yet are not neatly included in standard social-psychological item sets used in empirical analysis. We agree with Tadaki et al.’s (2017) assessment that "there is no corresponding consensus about what values are or which approaches to understanding values are useful and legitimate in particular settings" (p. 1) and that therefore conservation professionals must "encourage debate about environmental values to pivot away from theoretical gridlock" (p. 1).

Equipped with a pluralistic understanding of values, how can complex systems be changed? In her seminal essay, Meadows (1999) discusses different leverage points at which to intervene in systems. Interventions at shallow leverage points tackle stocks, flows, and parameters. They are relatively straightforward but result only in superficial change. A recent shift in conservation thinking is dominated by shallow leverage points - examples include agrienvironmental schemes, carbon payments, and the sustainable intensification of agriculture. Such measures operate within existing value systems, social order, and culture (Abson et al. 2017).

In contrast, interventions at deep leverage points are difficult but can bring about transformative system change. Among the deepest leverage points highlighted by Meadows (1999) are the goals being pursued in the focal system and the ability to change the paradigms on which these goals are based. In social-ecological systems, such goals are 
expressed though prevailing models of social order, culture, and associated values. These are fundamental to pursuing conservation outcomes. For example, cultures that do not affirm biocentric environmental values may find it difficult to curb illegal wildlife trade.

Conservation scientists cannot meaningfully speak of an extinction crisis (implying a need for transformative change) and yet act primarily on shallow leverage points. Rational application of systems thinking, not ideology, dictates that conservation professionals look deeper than that. The notion of leverage points highlights that the relationship between effort and outcome is not proportional - many small interventions will not amount to fundamental system change unless they go hand in hand with a change in the goals being pursued through the focal system. Shallow interventions may help pave the way for more fundamental changes (Geels \& Schot 2007), but by themselves, they cannot bring about transformation.

What then are the goals being pursued by the social-ecological systems of the Global North, and which values are associated with these? Arguably, the dominant goals embedded within these systems are rooted in a culture and values stemming from enlightenment, the industrial revolution, and the principles of capitalism (Eckersley 2016). For example, scholars have noted enlightenment thinking transformed nature from "something sacred into mere matter available for human manipulation" (Vogel 1996:52), and capitalism has embedded perpetual growth as a value within society (Robbins 2014). The onset of the Great Acceleration around the time of the industrialization (Steffen et al. 2007) strongly suggests that Western culture as it manifests today, along with its socioeconomic order and values, is one root cause of our (now global) extinction crisis. If that is so, it is only rational to question this culture and the values underpinning current trends and to seek change in these. This is the same logic that underpins the use of backcasting techniques to determine the scale of actions needed to achieve a designated goal (Dreborg 1996). Of course, values do not translate directly to 
behavior: the technical capacity for environmental degradation in the West has also been instrumental in shaping the present environmental crisis. But, pursuing societal change (in both developed and emerging economies) without challenging underlying values amounts to treating only symptoms, not causes.

Finally, although we agree that value shift is often observed in the context of substantial cultural change over long time frames, recent research shows that individuals' values can indeed shift relatively quickly in response to new situations and contexts. Raymond and Kenter (2016), for example, found that personal "transcendental values" (e.g. valuing "unity with nature") were influenced through deliberative processes with stakeholders. Bardi et al. (2014) found that individuals' values shifted over time after migrating to a new country. Although such value socialization occurs in response to new contextual factors, it clearly highlights the potential to explore how more intentional value shift might be possible. We do not argue that deliberatively shifting values is simple, but to deny any possibility of change appears to be self-defeating in a context of sustainability.

At the wider societal scale, the "complex nature of value formation" (Manfredo et al. 2017:6) suggests that, rather than precluding intentional value shift altogether, there is a need for research into how complex sociocultural dynamics can be influenced. The fact that few scientifically documented examples of deliberate value change currently exist is not surprising and should not be confused with evidence against it. Such change may be slow, but at the time scales relevant for extinctions, speciation, or human development, slow value change over the course of a human lifetime can still be considered extremely rapid. Broader social and institutional change is precisely the focus of the literature on sociotechnical systems transformation, which Manfredo et al. cite on page 7 (Geels 2002). Similarly, Everard et al. (2016) recently highlighted how key individuals or small-scale initiatives can 
scale up to precipitate broader socialization and institutionalization of values, leading to shifts in norms and practices. Indeed, such a ripple effect has been well observed in business, where strategic leadership leads to sustained cultural change in organizations (e.g., promoting the value of workplace safety in Alcoa by chief executive officer Paul O’Neill [Lagace 2002]).

Departing from a logic that social order and associated values cannot be changed, women still would not be voting today and racial discrimination would be at the same level it was 50 years ago. Soulé's (1985) normative postulates would still be widely held by conservation biologists today, and there would be no new conservation. Social values - along with culture and social order - do change, often within just a few decades, and such changes have the potential to transform societies, for better or worse. But neither changes in values nor culture come about without some kind of social movement that seeks change. Given the complexity of social systems, effective action may depend on identifying key moments of opportunity that provide the preconditions for change (e.g., environmental shock, institutional decline). However, the moment individuals and organizations stop seeking change, they self-sabotage their agency to actively create a better world.

Two conclusions arise from this discussion. First, a focus on shallow leverage points, by itself, is unlikely to bring about transformative system change. An exclusive focus on shallow leverage points is self-sabotage in that it prevents, by definition, transformation. If one believes that the current global system of human-environment relationships is not only superficially but also deeply unsustainable, deep leverage points must be considered. This includes changes to values, culture, and prevailing models of social order.

Second, interventions at shallow leverage points should not be dismissed altogether. Because of the potential for ripple effects (Everard et al. 2016), such interventions can lead to improvements within existing system states and may help create niches (sensu Geels \& Schot 
2007) where more fundamental societal change is possible. Pragmatic interventions operating within existing value systems and cultural contexts therefore can be part of the solution, but their limitations need to be recognized.

Different individuals will make different choices as to whether they want to bring about tangible change in the short term or help build momentum for transformative change. Those inclined to believe transformative change is needed are well advised to spend at least some of their time working on deep leverage points. Seeking to change the paradigms underpinning global systems - indeed, seeking value change - need not be a dreamy, ideological position. It is the rational response for individuals whose assessment is that transformative change is needed to reach a sustainable future. Not knowing how exactly to achieve social change, or value change, does not automatically mean we should stop trying. To us, it seems the extinction crisis cannot be solved within the mindset that created it.

\section{Acknowledgments}

Our work on leverage points was supported by the Volkswagenstiftung and the Niedersaechsisches Ministerium fuer Wissenschaft und Kultur, Germany (grant number A112269).

\section{Literature Cited}

Abson DJ et al. 2017. Leverage points for sustainability transformation. Ambio 46:30-39.

Bardi A, Buchanan K, Goodwin R, Slabu L, Robinson M. 2014. Value stability and change during self-chosen life transitions: Self-selection vs. socialization effects. Journal of Personality and Social Psychology 106:131-147.

Dreborg KH. 1996. Essence of backcasting. Futures 28:813-828.

Eckersley RM. 2016. Is the West really the best? Modernisation and the psychosocial dynamics of human progress and development. Oxford Development Studies 818:1-17. 
Everard M, Reed MS, Kenter JO. 2016. The ripple effect: Institutionalising proenvironmental values to shift societal norms and behaviours. Ecosystem Services:0-1.

Geels FW. 2002. Technological transitions as evolutionary reconfiguration processes: a multi-level perspective and a case-study. Research Policy 31:1257-1274.

Geels FW, Schot J. 2007. Typology of sociotechnical transition pathways. Research Policy 36:399-417.

Ives CD, Kendal D. 2014. The role of social values in the management of ecological systems. Journal of Environmental Management 144:67-72.

Lagace M. 2002. Paul O’Neill: Values into Action. Working Knowledge 4 November. Available from http://hbswk.hbs.edu/archive/3159.html (accessed June 2017).

Manfredo MJ et al. 2017. Why social values cannot be changed for the sake of conservation. Conservation Biology DOI: 10.1111/cobi.12855.

Meadows D. 1999. Leverage points: places to intervene in a system. The Sustainability Institute, Hartland Vermont.

Raymond CM, Kenter JO. 2016. Assessing and applying transcendental values to the management of ecosystem services. Ecosystem Services 21:241-257.

Robbins RH. 2014. Global problems and the culture of capitalism. Pearson, city.

Soulé M. 1985. What is Conservation Biology? BioScience 35:727-734.

Steffen W, Crutzen J, McNeill JR. 2007. The Anthropocene: are humans now overwhelming the great forces of Nature? Ambio 36:614-621.

Tadaki M, Sinner J, Chan KMA. 2017. Making sense of environmental values: a typology of concepts. Ecology and Society 22 DOI: 10.5751/ES-08999-220107.

Vogel S. 1996. Against nature. State University of New York Press, Albany. 